\title{
Identification of energy, environmental and economical optimal refurbishment scenarios for hotels in the Alps
}

\author{
Marie-Lise Pannier ${ }^{1}$, Hervé Boileau ${ }^{1}$, Catherine Buhé ${ }^{1}$ \\ ${ }^{1}$ Univ. Grenoble Alpes, Univ. Savoie Mont Blanc, CNRS, LOCIE, 73000 Chambéry, France
}

\begin{abstract}
It is a challenge to achieve an affordable and energy efficient building renovation that leads to a decrease of the environmental impacts, as many objectives and various renovation actions should be considered. In this study, the many-objective optimisation algorithm NSGA-III is applied, for the first time in building energy. The solutions search process of NGSA-III makes it more efficient when dealing with more than three objectives. It was included in a simulation platform consisting in a dynamic building energy simulation (DBES) tool, a building life cycle assessment (LCA) tool and a cost database, in order to guide the decision towards good energy-environment-cost renovation solutions for a hotel in the Alps. Its application helps identifying good renovation strategies for the hotel. The results robustness to the climate data is then assessed.
\end{abstract}

\section{Introduction}

Refurbishment is a key issue to reduce the various environmental impacts caused by the building stock (European Parliament 2016). Among the existing buildings, family hotels in the Alpine area are particularly high energy consumers. They are mostly old buildings, having specific climatic (cold climate) and use (strong seasonality effect) conditions. Furthermore, guests have high expectations concerning the services provided by the hotel and they take less care to their consumptions than at home.

A successful mountain hotel renovation should be affordable for the hoteliers, increase the guest comfort and lead to energy savings as well as to a reduction of the impacts caused to the environment. Many criteria, with potentially contradictory effects, should therefore be taken into account. In addition, numerous renovation actions can be applied on a building. It may be difficult to identify which combinations of renovation actions are the most appropriate, especially when the budget is limited and in presence of constructive or context specific constraints. Optimisation algorithms are often used in building simulation to solve such complex problems. An example can be found in Recht et al. (2016) for the ecodesign of a plus-energy house.

Being part of the French-Swiss Interreg research project CREnHOM, the present work is based on the evolutionary many-objective optimisation algorithm NSGA-III (Deb and Jain 2014; Jain and Deb 2014) to efficiently identify optimal refurbishment scenarios for mountain hotels. NSGA-III was preferred to NSGA-II (Kalyanmoy Deb and al. 2002) as it is more adapted when dealing with more than three objectives, i.e. fewer simulations and less time are required to find the best compromises. This is to our knowledge the first application of NSGA-III in the building simulation context. The evaluation of the energy, environmental and cost criteria was performed using a DBES tool, a building LCA tool and a cost database. Algorithm and tools are introduced in the Methodology section. The methodology is applied to a hotel and the optimisation problem is described in the Case Study section. Then the optimisation results are presented and discussed.

\section{Methodology}

The applied methodology is shown in figure 1. Firstly, the optimisation problem is stated in describing what is the scope of the study, how looks the hotel to be refurbished, what could be the renovation actions, what are the energy, environment and cost objectives to minimise and what are the constraints to consider. Then, the optimisation algorithm finds the best compromises. Different combinations of renovation actions are found and their performances are assessed for each objective using adapted simulations tools. Finally, the optimisation algorithm provides a set of optimal refurbishment scenarios. The optimality is assessed in the sense of Pareto: each optimal solution can not perform better on an objective without making worse the performance of at least one other objective. Some input hypotheses are then refined to check the solutions robustness.

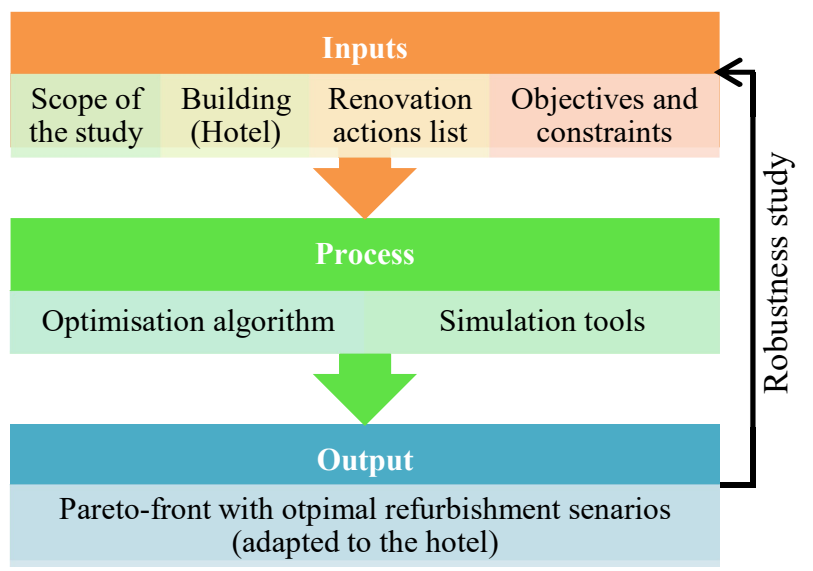

Figure 1: Optimisation methodology applied 


\section{Optimisation algorithm}

Using a full factorial sampling to test all combinations of refurbishment actions is often not practically manageable. A more efficient optimal solutions search strategy is achieved using optimisation algorithm. Among them, genetic algorithms such as NSGA-II (Kalyanmoy Deb et al. 2002) or NSGA-III (K. Deb and Jain 2014; Jain and Deb 2014) based on the theory of evolution to gradually improve the performances of a population. A population consists of individuals having genes. In our case, each gene is a possible renovation action (e.g.: windows change) that can take different allele values (e.g.: double or triple glazing). An individual is thus a combination of renovation actions. Finally, a population describes, in our case, a wide range of refurbishment scenarios that can be set up on a same building. In genetics algorithm, the population adapts itself (according to objectives and constraints) and improves generation by generation. At each generation, parent individuals create offspring having new characteristics: the genomes of these late are combinations of the parent's ones (through the crossover operator) with, potentially, some mutations (through the mutation operator). For the next generation, elite members (i.e. parents or offspring performing well on all objectives) are preserved, so that the population converges towards the best compromises.

When dealing with four or more objectives, the search process is slowed down in classical evolutionary algorithm and NSGA-III has been proposed to face this problem. The steps of NSGA-III are described hereafter:

1. A set of reference points well distributed on a normalised hyperplane is defined. These help ensuring diversity among the solutions. The number of reference points $\mathrm{H}$ depends on the number of objectives $\mathrm{M}$ and the number of divisions on each objectives $p$, as illustrated in equation (1) and in the example on figure 2 .

$$
H=\left(\begin{array}{c}
M+p-1 \\
p
\end{array}\right)
$$

2. An initial population consisting of $\mathrm{N}$ individuals is randomly generated and the individuals performances are evaluated.

3. [Only in presence of constraints] A tournament selection is applied to parents to determine which ones are allowed to create offspring. This emphasises feasible solutions or solutions with a small constraint violation.

4. Parents create offspring. Crossover and mutation are applied with specific probabilities of occurrence. The offspring performances are then evaluated.

5. $\mathrm{N}$ individuals are selected (among the current $2 \mathrm{~N}$ population consisting of $\mathrm{N}$ parents and $\mathrm{N}$ offspring) for the next generation, as decribed bellow:

5a [In absence of constraints] The $2 \mathrm{~N}$ individuals are sorted according to the front they belong to (Pareto front: F1, front of rank 2: F2...). [In presence of constraints] Feasible solutions are sorted according to the front they belong to. Then, unfeasible solutions are placed in the next fronts according to their constraints-violation levels.

5b. All individuals from the best fronts $F_{1}, F_{2}, \ldots$ are selected for the next generation, until the front $F_{i}$ for which the population size exceed $\mathrm{N}$ for the first time.

5c. Only some individuals from $F_{i}$ are included in the next generation to reach exactly $\mathrm{N}$ individuals. There are chosen to maximise the diversity. While the individuals having the largest crowding distance are chosen in NSGA-II, the NSGA-III algorithms suggest choosing individuals closed to the reference points. The population members are therefore normalised and associated to a reference point. Then, individuals from $F_{i}$ are preserved if they are associated to a point having fewer associations.

6. Steps 2), 3) and 4) are repeated until a stop criterion (e.g. a number of generations) is reached.

It is advises to choose $\mathrm{N}$ close to $\mathrm{H}$ ( $\mathrm{N}$ being the smallest multiple of four higher than $\mathrm{H}$ ). Thus, NSGA-III does not require additional parameters compared to NSGA-II.

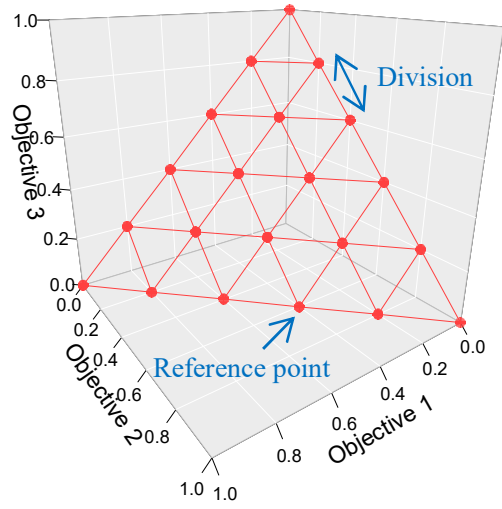

Figure 2: 21 reference points on a normalised reference plane for a three-objective problem with five divisions

\section{Simulation tools}

The objective to be minimised are quantitative criteria related to the energy consumption, the environmental impacts and the renovation costs.

The energy consumptions are evaluated using the DBES tool COMFIE (Peuportier and Blanc-Sommereux 1990). Buildings are divided into thermal zone considered at homogeneous temperature which are then meshed. A thermal balance is performed on each mesh and the operative temperature, and the heating and cooling loads are then obtained for each thermal zone. The simulation was run using a 30 min time step.

The building LCA tools Pléiades ACV (Polster 1995; Popovici 2005) is used to assess the environmental impacts caused by the building along its entire life cycle (i.e. construction, use phase, renovation and end-of-life). Due the long building lifetime, the use phase, often leads to the highest impacts (Anand and Amor 2017). COMFIE is thus coupled to the LCA tool to assess more precisely the energy related impacts. 12 environmental indicators can be calculated in order to reflect the 
diversity of problems or damages caused to the environment (Peuportier 2005). The environmental database ecoinvent v2.2 is used to link all building processes and products with their life cycle inventories and impact assessment data.

The renovation costs are evaluated using a cost database currently under development in the frame of the CREnHOM project. Costs are compiled for the uninstallation, installation and maintenance of the building components to be refurbished. This database only includes refurbishment actions that are suitable in mountains area, e.g. components of the building envelope should resist to a certain weight of snow.

\section{Case study}

This section presents the inputs of the optimisation methodology (figure 1), that are related to the case study.

The aim of our study is to identify good energyenvironment-cost compromises for the refurbishment of a two-star family hotel located in the ski resort of Zinal, Wallis, Switzerland. This hotel has 23 guestrooms and a restaurant. Since it was built in the 1920s, this stone building has been subject to several renovations (as a wall insulation in the 1970 s, a fuel boiler replacement in the late 1990s and a windows change a decade ago).

\section{Scope of the study}

A hotel is investigated in this study. For such a building, a refurbishment often means redecorating or remodelling guestrooms, or replacing furniture or equipment. In this study, the refurbishment means an energy renovation and the changes concern the envelope and systems. The environmental impacts are related to the entire hotel. For the use phase, only the heating, hot and cold water supply and the wastewater treatment are included in the scope; services are not taken into account. In a next step, laundry, catering services, transportation of guest and employees could also be included and the impacts could be calculated per guest night stay, as it is often performed in hotels LCA (Filimonau et al. 2011).

Renovation scenarios are assessed in the study. This has several implications. First, only the building components affected by the renovation are considered. Cost and environmental impacts relate to: i) the end-of-life of the old building components and ii) the new components fabrication, transportation, installation and potential maintenance. No costs or impacts are linked to unchanged components. Second, only the current renovation is studied. The analysis time was set to 20 years and no further renovation is supposed to happen during that period. All processes taking place later are excluded. Third, we assume that the renovation actions are set in year 0 and that the building energy consumption, operating cost and impacts remain unchanged for the next 20 years.

\section{Hotel energy and environmental modelling}

After the modelling of the building geometry (figure 3), the envelope and systems were described using data from a CECB (Swiss energy efficiency certificate). 9 thermal zones have been defined to assess the operative temperature and thermal load more precisely. Rooms with different uses or on different floors are placed in different thermal zones. The hotel operation is modelled using scenarios. Each zone has specific scenarios for the temperature set point, occupant's presence, internal load and ventilation. The seasonality effect of the hotel occupancy is taken into account, as the hotel receives more guests during the ski season and in summer and is closed off-season. The variability of the guests behaviour in the hotel is not studied and the same heating temperature setpoint is considered in all rooms during the hotel opening $\left(21,5^{\circ} \mathrm{C}\right)$. The meteorological data for Zinal, used in the energy simulation, comes from the European tool PVGIS. The water consumption is assumed to be 2801 per guest and per day, including 801 for hot water - based on data from Puig et al. (2017).

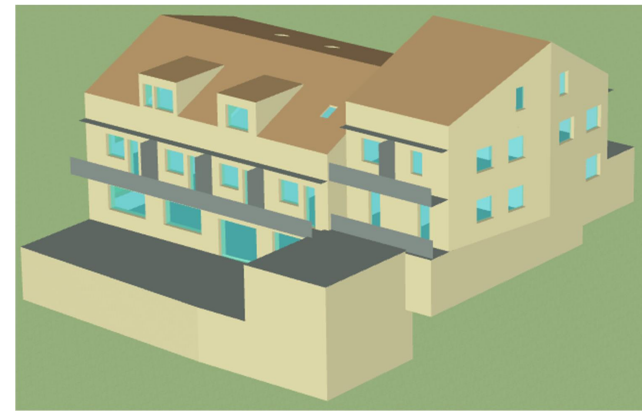

Figure 3: Hotel modelling in Pléiades+COMFIE

\section{Studied renovation actions}

The solution search space is defined by eight genes representing the hotel. Three of them characterise the external wall, roof and first floor (being the ceiling of the unheated basement). Many settings are possible for each renovation: e.g. for the exterior walls: internal or external insulation, with cladding or coating and using several insulation materials. The possible wall compositions have been defined with industrial partners of the project and they are practicable renovation actions for a mountain hotel. Three other genes define the level of insulation in the external wall, roof and first floor. The targeted U-value is either the U-value expected for renovation in the French thermal regulation, or the Uvalue expected in the EnerPHit standard (passive house retrofitting). One gene relates to the windows change. New double or triple glazing can be installed on one or more façade. The last gene concerns the device for heating and hot water. As the hotel could be connected to an existing district heating in the future, this option has been studied besides the boiler replacement. All renovation actions are summarised in table 1.

\section{Objectives of the optimisation}

The study aims at minimising the energy consumption, environmental impacts and spending of the hotel through optimal combinations of renovation actions.

The primary energy consumption is the first objective. It includes the energy for the hotel operation (based on the heating load calculated in COMFIE, weighted by the boiler efficiency) as well as the grey energy for the components fabrication and end-of-life. 
Table 1: Renovation actions

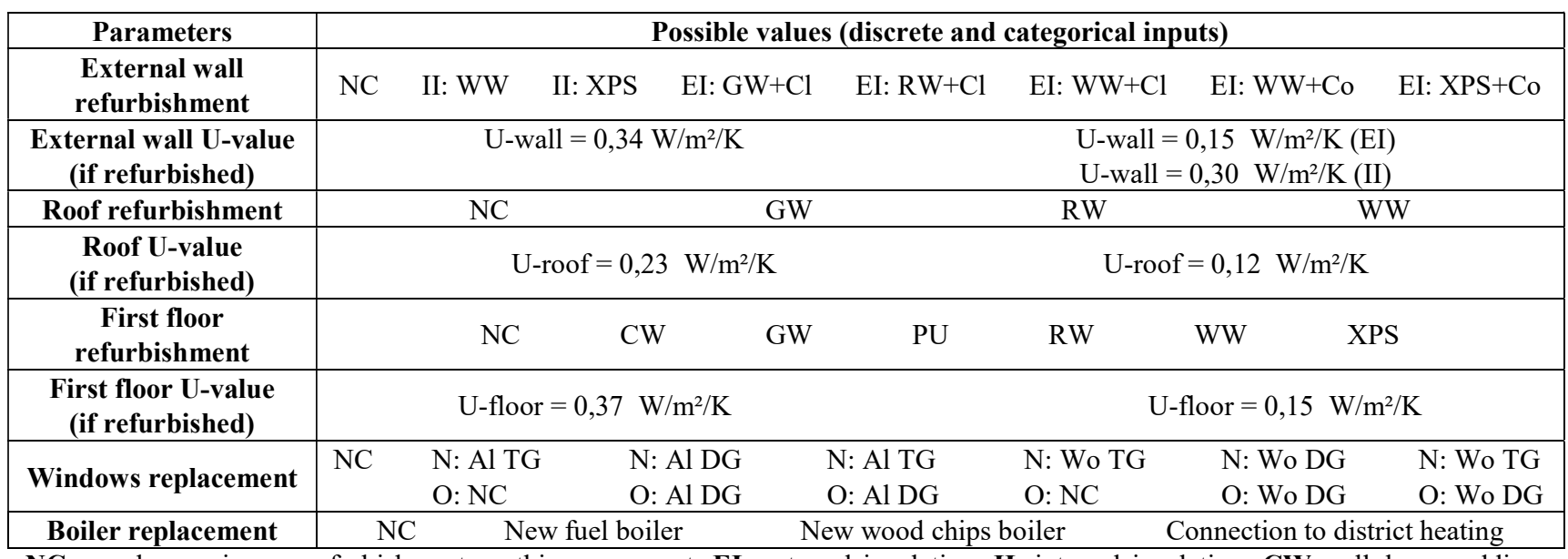

NC: no change, i.e. no refurbishment on this component; EI: external insulation; II: internal insulation; CW: cellulose wadding; GW: glass wool; PU: polyurethane; RW: rock wool; WW: wood wool; XPS: extruded polystyrene; Cl: cladding; Co: coating; N: north; O: other orientations (east, south and west); Al: aluminium frame; Wo: wood frame; DG: double glazing; TG: triple glazing.

Twelve environmental indicators are calculated for the manufacture of new components, the processes operating during the use phase and the end-of-life of building components to be refurbished. We chose to minimise two objectives related to two indicators: the climate change indicator (IPCC 2013) and an indicator quantifying the damage caused to ecosystems due to toxic substances (Goedkoop et Spriensma 2000). More indicators could be included in a next step in order to cover a wider range of potential impacts caused to the environment along the building life cycle.

The fourth objective to minimise is the total cost (investment, operation and maintenance). The costs are calculated using the database developed in the project. It should be noticed that this database is currently under development. Assumptions have been done to complement the first data available.

\section{Constraints defined in the algorithm}

In this study, no constraints were considered. It is intended to include a constraint on the investment cost in a next step in order to ensure that renovation scenarios are affordable. Another constraint will be on the energy level of performance to reach.

\section{Algorithm settings}

Eight divisions are considered on each of the four objectives in the NSGA-III algorithm. According to (1), 165 reference points helps describing the Pareto front and the population consists of 168 individuals (smallest multiple of four higher than 165). That means that 168 combinations of renovation actions are studied in each generation. A single-point binary crossover is used. The crossover and mutation rates are set to 80 and $20 \%$ respectively. The number of generations was chosen to reach convergence.

\section{Results of the case study}

\section{Convergence of the algorithm}

After 6 generations, all the 168 individuals were Pareto optimal. The optimisation was proceeded to increase the diversity among individuals. From generation 27, the
Pareto front stabilised, the involved reference points staying the same and the individual's characteristics being nearly identical. The results of the optimisation at generation 27 have been obtained after 4536 simulations (compared to 50176 simulations for the full factorial sampling) and more than 6 hours calculation were required on a 2 core computer.

\section{4-dimensional Pareto front}

The 4-dimensional Pareto front is shown in figure 4, using six graphs, to visualise each pair of objectives. A seventh graph displays, for one pair, the last Pareto front and the randomly sampled initial population. Compared to the first solutions, the Pareto front solutions at generation 27 are closer to each other's, as the optimal solutions are placed in a reduced search space. Discontinuities are observed in the front. They are linked to the choice of the device for heating and supplying hot water. This is obvious from the initial population, which is clearly split in four parts according to this choice. Using a fuel boiler (new or old) leads to much higher $\mathrm{CO}_{2}$ emissions. The wood boiler causes more damage to ecosystems than other systems. In addition, using the old fuel boiler, that has a lower efficiency leads to both higher primary energy consumptions and use costs.

\section{Characteristics of the Pareto front}

The characteristics of individuals belonging to the Pareto front are presented in figure 5. This graph is split in 5 parts, each one describing the renovation actions performed on a building component. The number of occurrences of the actions are mentioned. Note that characteristics of duplicated points only appears once. For wall, roof and floor renovations (genes 1 to 6), the insulation level (genes 2; 4 and 6) is combined with the renovation action (genes 1; 3 and 5). One colour is used for each action, and if the regulation U-values are used, the bar is completely filled with the colour, while coloured hatching are used for the EnerPHit U-values.

Using this graph, one can read that among the 10 occurrences of external walls renovation with wood wool and a cladding $(\mathrm{WW}+\mathrm{Cl}), 6$ have an EnerPHit 

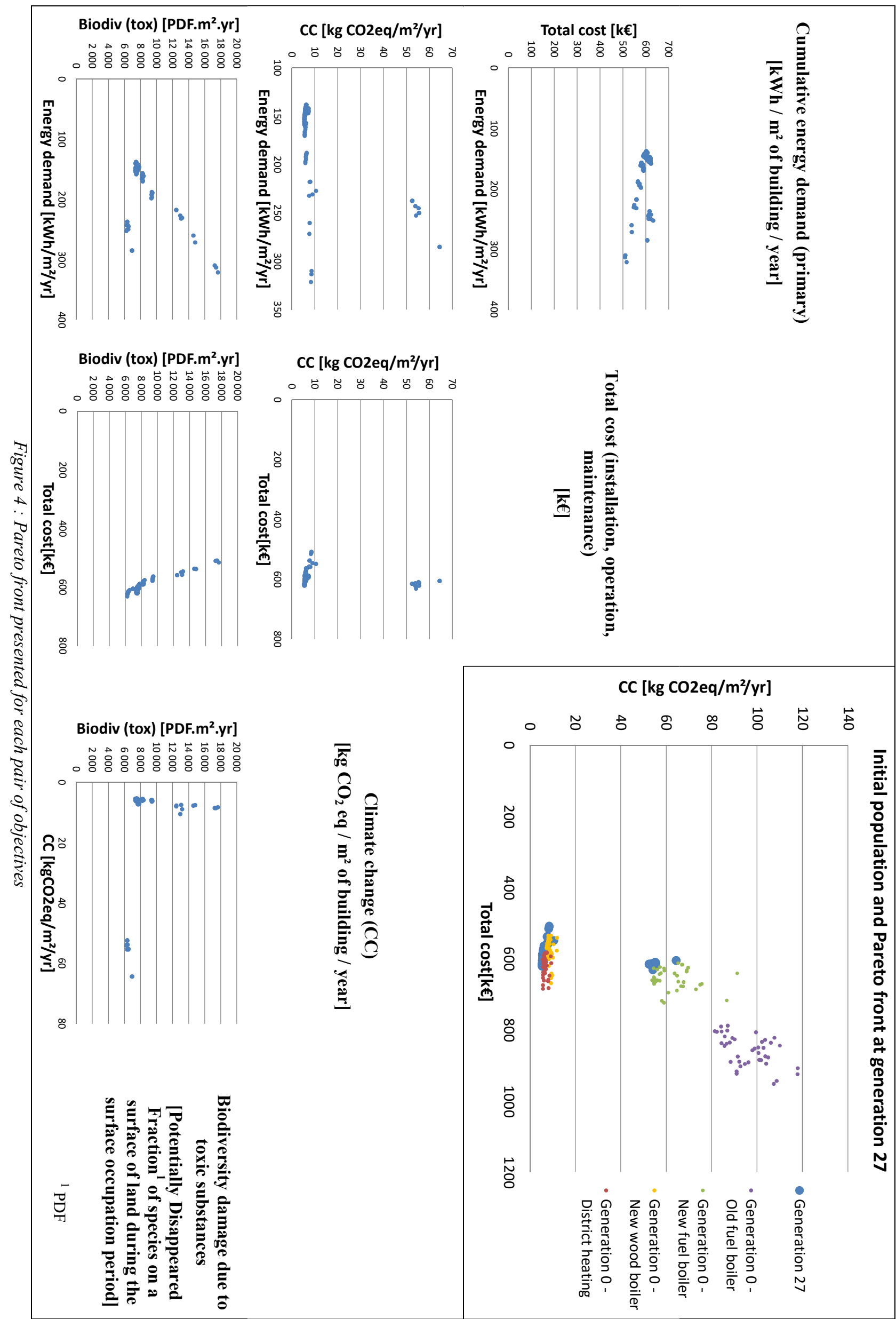


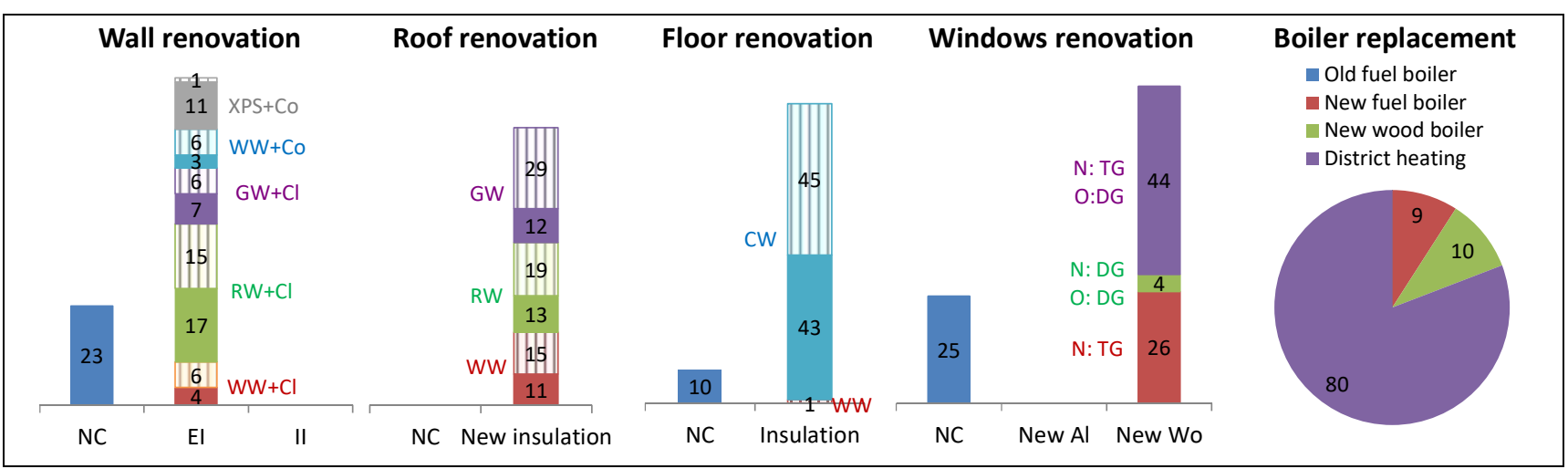

Figure 5 : Characteristics of the Pareto front

standard insulation level. For the wall, refurbishing is a good option in three quarters of the cases. If a refurbishment is performed on this component, an external insulation (EI) is preferred to the internal one. No clear tendency appears on the choice of an insulation material or level.

It is clear from figure 5, that a roof refurbishment should be performed on the hotel. This component is always refurbished in the optimal solutions. Many guestrooms are located in the attic space and have a large contact surface with the outside through the roof, leading to high heat losses. Renovating the roof helps reducing the heating load, and thus the environmental impacts of the use phase and the operational costs. It is more difficult to conclude concerning the choice of an insulation material, but a high insulation level should be preferred.

Contrarily to wall and roof, the floor has not been insulated during the previous renovations. It is now a good option to insulate it and the cellulose wadding is the preferred insulation material to perform it.

The windows renovation is a good option; even more if wood is used for the new windows frame and if triple glazing windows are placed on the northern facade while mounting double gazing on other orientations. Compared to aluminium, wooden windows are cheaper and cause less environmental impacts for their fabrication.

Last, the old fuel boiler should be replaced by another system. Connecting the hotel to the district heating is the best option to minimise all criteria. Replacing the old fuel boiler by a new fuel boiler or by a wood boiler is advised in some cases.

Through the study of the characteristics of Paretooptimal individuals, it is possible to guide the decision towards renovation solutions that are optimal regarding the set problem and the considered objectives.

\section{Results' robustness}

In order to check the results robustness, a study was performed on the effect of the chosen meteorological data. Three typical meteorological files were available for the hotel location on PVGIS. They are based on the following sets of years: 2005 to $2014 ; 2006$ to 2015 and 2007 to 2016. Depending on the file, the non-refurbished hotel heating load varied from $215 \mathrm{kWh}$ to $237 \mathrm{kWh}$, see table 2. Three optimisations were performed, each one using another meteorological file. In order to reduce the computation time, the optimisation included only three objectives: the total cost, the primary energy demand and the climate change indicator. The number of divisions per objective was set to 12 , so the population consists in 92 individuals. In addition, 20 generations were studied. Each optimisation required 2,5 hours of calculation and at the end, all individuals belonged to the Pareto front.

Table 2 : Heating load of the non-refurbished hotel

\begin{tabular}{|l|l|l|}
\hline $\mathbf{2 0 0 5}-2014$ & $\mathbf{2 0 0 6 - 2 0 1 5}$ & $\mathbf{2 0 0 7 - 2 0 1 6}$ \\
\hline $222 \mathrm{kWh} / \mathrm{m}^{2} / \mathrm{yr}$ & $215 \mathrm{kWh} / \mathrm{m}^{2} / \mathrm{yr}$ & $237 \mathrm{kWh} / \mathrm{m}^{2} / \mathrm{yr}$ \\
\hline
\end{tabular}

The Pareto fronts are compared in figure 6 . Although the fronts are rather closed to one another, the three fronts rank according to the climate severity. The 2006-2015 data that had the lowest heating load for the nonrefurbished hotel, leads to the lowest front. Inversely, the 2007-2016 data file leads to the highest front.

The characteristics of the Pareto fronts are summarised in figure 7. Duplicated individuals have been removed from the results. As the number of unduplicated individuals is different in each front, the share of each renovation action is presented. Furthermore, the Pareto fronts characteristics are sorted according to the climate severity (the data file leading to the lowest heating load for the non-refurbished hotel appears first). No clear tendencies are observed for the implementation of actions in relation with the climate severity. The fronts have similar characteristics for all climate file. In addition, the characteristics are closed to the ones observed in figure 5. For instance, the roof renovation is always suggested; cellulose wadding is the preferred insulation material for the floor; and the existing windows should be replaced by new wooden ones. For the choice of the device for heating and providing hot water, wood boiler or a connection to the district heating are the only options suggested, which is different from the previous optimisation. This can be explained by the choice of the objectives. Choosing the wood boiler was the worst option for the damage to ecosystem indicator that is not included in the current study. The wood option is therefore more often selected now. The new fuel boiler option is no more chosen as it leads to much higher greenhouse gases emissions.

To sum up, despite the slight differences in the fronts, the results are quite robust to the choice of the meteorological data in this study, as the set of renovation 
actions stays almost the same. Instead of typical meteorological file, using extreme data file, describing very harsh or mild weather, could lead to more differences in the solutions characteristics. Furthermore, we observed that a change in the optimisation problem (e.g. number of objectives) leads to a difference in the renovation actions selection.

\section{Discussion}

Through the performed optimisations, it was possible to identify optimal refurbishment scenarios of the studied hotel. The proposed methodology, adaptable to other building types, is useful to guide the decision making towards the best compromise in a given context.

The obtained results should not be generalised, as they are dependent on the optimisation problem and the hypothesis. For instance, the cost database been under development, many costs are uncertain and should be further investigated and subject to sensitivity studies.

The case study will be further analysed. An investment constraint will be added in order to ensure that the chosen scenarios are affordable. Then, the set of objectives will be changed in order to both cover all topics of the sustainable construction and avoid potential topics overlapping. In addition to the cost, using indicators describing damages caused to the three main areas of protection considered in LCA (human health, biodiversity and resources) seems to be an interesting option in that sense.

Furthermore, the results robustness towards some hypotheses (e.g. variation of occupation) and towards the algorithm settings will be further studied.

After the identification of good compromises using the

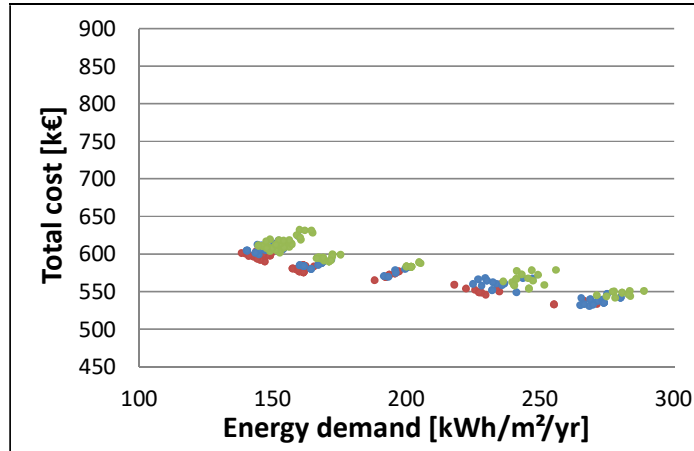

- 2005-2014 typical meteorological data

- 2006-2015 typical meteorological data

- 2007-2016 typical meteorological data
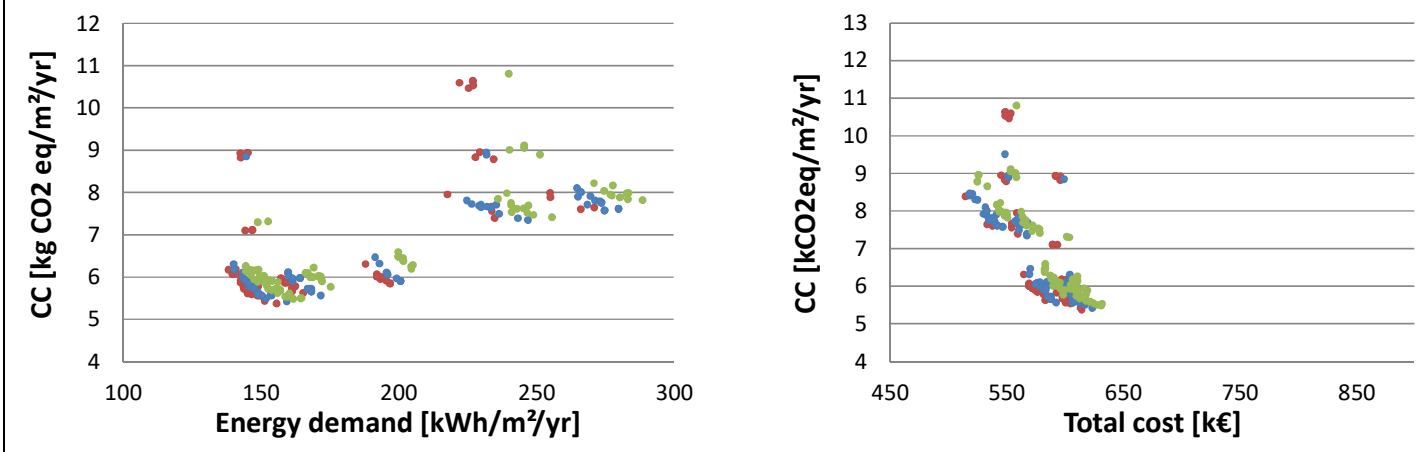

Figure 6 : Comparison of Pareto fronts for different meteorological files

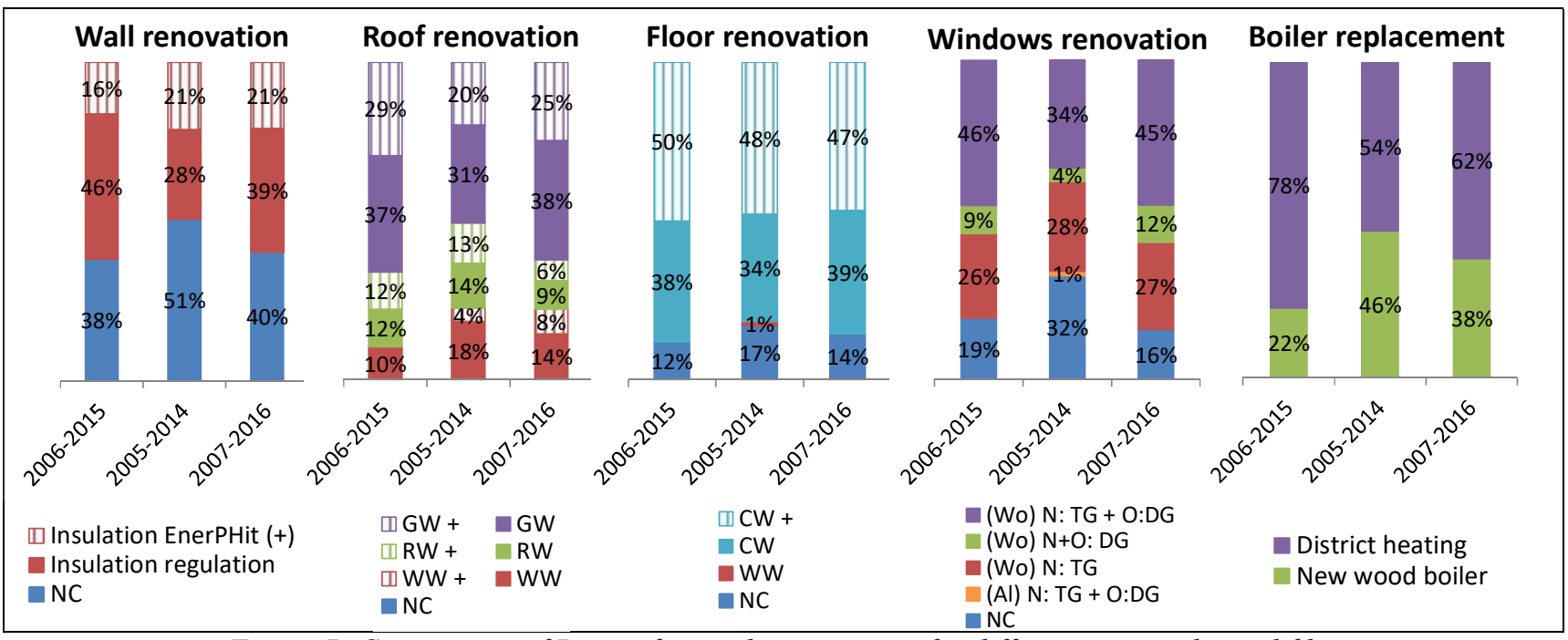

Figure 7: Comparison of Pareto fronts characteristics for different meteorological files 
Pareto front solutions, the decision maker has to choose the refurbishment solution that will be set up on the hotel. Multicriteria decision analysis process can be used to find the best solution according to quantitative and qualitative aspects of importance for the hotelier, e.g. choosing a solution with actions that guests are able to perceive in order to increase the hotel attractiveness.

\section{Conclusion}

In this paper, the many-objective NSGA-III optimisation algorithm has been applied in order to identify wellperforming refurbishment scenarios regarding energy, environment and cost criteria. Four optimisation objectives were considered and assessed using the DBES tool COMFIE, the building LCA tool Pléiades ACV, and the building cost database developed within the CREnHOM project. A wide range of renovation actions have been studied on the case of a two-star family hotel located in a ski resort in Switzerland. Through the analysis of Pareto-optimal solutions, good combinations of refurbishment actions have been identified. These information are useful to provide a decision-aid. In order to study the potentials change in the optimal renovation scenarios, a first robustness check has been performed. It relies on the comparison of optimisation results given by three typical meteorological files for the same location, but that are based on different sets of years. The results were quite robust to this hypothesis but a more systematic robustness check is expected in order to increase the results confidence.

\section{Acknowledgments}

This work has been performed in the frame of the Interreg project CREnHOM (http://www.crenhom.org/). The project is supported by the European Territorial Cooperation Program Interreg V France-Switzerland and was founded by a European grant of $607776,49 €$ via the European Regional Development Fund (ERDF), by federal credits from Interreg Switzerland in the amount of $150001 \mathrm{CHF}$ and by $123999 \mathrm{CHF}$ of cantonal and municipal funding. The authors want to acknowledge all project partners, especially Jeanne Goffart for her help regarding the meteorological data, as well as the company IZUBA énergies for their support.

\section{References}

Anand, Chirjiv Kaur, and Ben Amor. 2017. «Recent developments, future challenges and new research directions in LCA of buildings: A critical review ». Renewable and Sustainable Energy Reviews 67: 408-16. https://doi.org/10.1016/j.rser.2016.09.058.

Deb, K., and H. Jain. 2014. « An Evolutionary ManyObjective Optimization Algorithm Using ReferencePoint-Based Nondominated Sorting Approach, Part I: Solving Problems With Box Constraints ». IEEE Transactions on Evolutionary Computation 18 (4): 577-601. https://doi.org/10.1109/TEVC.2013.2281535.

Deb, Kalyanmoy, Amrit Pratap, Sameer Agarwal, et TAMT Meyarivan. 2002. «A fast and elitist multiobjective genetic algorithm: NSGA-II ».
Evolutionary Computation, IEEE Transactions on 6 (2): 182-197.

European Parliament. 2016. «Boosting Building Renovation: What Potential and Value for Europe? » IP/A/ITRE/2013-046 PE 587.326. http://www.europarl.europa.eu/RegData/etudes/STU D/2016/587326/IPOL_STU(2016)587326_EN.pdf.

Filimonau, Viachaslau, Janet Dickinson, Derek Robbins, and Mark A. J. Huijbregts. 2011. "Reviewing the carbon footprint analysis of hotels: Life Cycle Energy Analysis (LCEA) as a holistic method for carbon impact appraisal of tourist accommodation $»$. Journal of Cleaner Production 19 (17): 1917-30. https://doi.org/10.1016/j.jclepro.2011.07.002.

Goedkoop, M., et R. Spriensma. 2000. «The Ecoindicator 99: A damage oriented method for life cycle impact assessment». PRé Consultants, Amersfoort, The Netherlands.

IPCC Working Group I. 2013. « Climate Change 2013: The Physical Science Basis, Contribution of Working Group I to the Fifth Assessment Report of the Intergovernmental Panel on Climate Change $»$. Cambridge University Press.

Jain, H., and K. Deb. 2014. « An Evolutionary ManyObjective Optimization Algorithm Using ReferencePoint-Based Nondominated Sorting Approach, Part II: Handling Constraints and Extending to an Adaptative Approach ». IEEE Transactions on Evolutionary Computation 18 (4): 577-601. https://doi.org/10.1109/TEVC.2013.2281535.

Peuportier, Bruno. 2005. «Towards sustainable neighbourhoods, the eco-housing project». In $I V$ International Conference "Climate change - energy awareness - energy efficiency ». Visegrad, Hungary, 8-10 June 2005.

Peuportier, Bruno, and Isabelle Blanc-Sommereux. 1990. "Simulation tool with its expert interface for the thermal design of multizone buildings $»$. International Journal of Solar Energy 8 (2): 109-20. https://doi.org/10.1080/01425919008909714.

Polster, Bernd. 1995. «Contribution à l'étude de l'impact environnemental des bâtiments par analyse du cycle de vie ». PhD Thesis, École nationale supérieure des MINES de Paris, 268p.

Popovici, Emil. 2005. "Contribution to the life cycle assessment of settlements ». PhD Thesis, École Nationale Supérieure des MINES de Paris, 244p.

Puig, Rita, Eylem Kiliç, Alejandra Navarro, Jaume Albertí, Lorenzo Chacón, and Pere Fullana-i-Palmer. 2017. "Inventory analysis and carbon footprint of coastland-hotel services: A Spanish case study ». Science of The Total Environment 59: 244-54. https://doi.org/10.1016/j.scitotenv.2017.03.245.

Recht, Thomas, Patrick Schalbart, and Bruno Peuportier. 2016. «Ecodesign of a "plus-Energy" House Using Stochastic Occupancy Model, Life-Cycle Assessment and Multi-Objective Optimisation ». In Building Simulation \& Optimisation, 8. Great North Museum, Newcastle, 12-14 September 2016. 